\title{
I CONGRESSO BRASILEIRO DE ECONOMIA 1943.
}

atores, intelectuais e ideologias na constituição de uma

consciência de classe entre os industriais e a

\section{consolidação do projeto industrialista}

Arthur de Aquino*

Resumo Este trabalho consistiu em duas tarefas básicas: o mapeamento e a sistematização dos Anais do I Congresso Brasileiro de Economia e o cruzamento com a ação de Roberto Simonsen, líder do segmento industrialista. A liderança de Simonsen caracteriza um momento sui generis na formação de uma consciência corporativa de classe entre os industriais, uma vez que eles superam o imediatismo conjuntural de suas demandas. A importância do estudo em questão está na compreensão de um projeto de nação por parte dos industriais, cujo contexto possui Simonsen como o ator que consegue ordenar o segmento industrialista, aprofundando e dando consistência à argumentação. Os objetivos da pesquisa consistiram na análise da agenda do Congresso, seus temas, debates e recomendações, com o fim de identificar os paradigmas teóricos, políticos e econômicos do período, assim como cruzar com a obra de Simonsen e o contexto histórico. O texto conclui com os principais pontos do projeto industrialista, extraídos das recomendações do Congresso ao governo.

Palavras-chave Roberto Simonsen; pensamento social brasileiro; industrialismo.

* Mestrando pelo Programa de Pós-Graduação em Ciência Política da Universidade Estadual de Campinas. 


\section{Brazilian Congress of Economy 1943: actors, intellectuals and ideologies in the constructions of a class consciousness betwenn the industrials and the consolidation of the industrials project}

Abstract This paper concerns in two main effors: the maping and systemization of I Congresso Brasileiro de Economia historical records, and across with Roberto Simonsen's action, until industrialist segment leader. The Simonsen's leadership defines a sui generis moment in a making of a corporative class conscious among industrial entrepreneurs, so they overcomes the transitory immediatism of his demands. The importance of this paper in fact is the understanding of nation's project by industrials side, whose context have Simonsen how the political actor with gets to organize the industrialist segment, elaborating and offer consistence to argumentation. The research objectives concerns in agenda analisys of I Congresso, his issues, debates, and recommendations, to deal of indentify the politica, economics, and theoretical paradigms of period, such as to combine with Simonsen's work and historical context. The paper concludes with main points of industrialist project, extracted of Congress recommendations to govern. Keywords Roberto Simonsen; Brazilian social thought; industrialism.

\section{INTRODUÇÃO}

Os objetivos deste trabalho consistiram na análise da agenda do I Congresso Brasileiro de Economia, com o fim de detectar o sentido ideológico dos debates. Em seguida, a identificação do cenário histórico, social e ideológico das relações entre conjuntura socioeconômica e as prioridades reivindicadas pelos industriais, seguida do acompanhamento das votações na comissão de redação.

Assim, foi possível detectar as influências dos paradigmas teóricos (tanto na produção bibliográfica dos autores quanto no debate público), políticos e econômicos do período: keynesianismo, planejamento socialista, pré-formação das ideias cepalinas. 
O conjunto dos objetivos propostos trabalha com a perspectiva de entender como ocorreu pontualmente nesse período o debate sobre o fim do laissez-faire; explicar o comportamento dos industriais do período enquanto classe para si, tomando por vista - e mesmo indagando sobre o porquê - o lócus do debate e as medidas adotadas pelos governos posteriores, tendo em vista as reivindicações do segmento industrialista.

O I Congresso Brasileiro de Economia aconteceu nas dependências da Associação Comercial do Rio de Janeiro, entre 18 de novembro e 15 de dezembro daquele ano. Esse Congresso entra em um mesmo movimento, de acordo com Carone (1977, p. 298), com o I Congresso Brasileiro da Indústria, realizado em São Paulo, em 1944, e a I Conferência Nacional das Classes Produtoras (CONCLAP), de 1945, de posições mais maduras, concretas e centradas no segmento industrial - e não mais em cada empresa ou empresário isoladamente.

A importância desses congressos industriais da década de 1940 explica o comportamento dos industriais como atores sociais, principalmente no tocante à questão do conflito entre liberalismo econômico (defendido por Gudin) e desenvolvimentismo/industrialismo (defendido por Simonsen).

Essa disparidade no que toca à intervenção do Estado na economia levou ao estudo das matrizes do pensamento econômico brasileiro do período, uma vez que, na década de 1940, tornou-se clara a contradição entre corporativismo e liberalismo, cuja temática vai da necessidade de intervenção, passando pela crise que questiona os limites do laissez-faire. Dessa maneira, é necessário considerar as diferentes influências teóricas do período (que passam pela recepção das teses de List (1989), Keynes (1965) e Manoilesco (1938), no debate entre regulacionismo e liberalismo.

Também foi pertinente elucidar o porquê de os empresários pedirem proteção do Estado. Os congressos industrialistas da década de 1940 estão no centro dos debates por serem o momento no qual os industriais tomam sua consciência corporativa de classe e a defesa de seus interesses e também 
cujos debates tomarão a frente do projeto industrialista. A preocupação passou, portanto, à identificação dos atores e das ideias antecedentes à consolidação da industrialização pesada ${ }^{1}$; como é também de extrema importância para o pleno entendimento do pensamento econômico e político do período.

Simonsen, dentro do pensamento industrial, significou uma superação entre seus pares, uma vez que precisou definir conceitualmente, de maneira mais rigorosa e concisa, suas acepções teóricas. É por isso que nesse momento as reivindicações industrialistas superam o imediatismo das demandas individuais dos industriais e passam a constituir-se como um projeto de nação. Foram pontos cruciais nessa elaboração político-intelectual: a conciliação de classes, a ideia de progresso e o povoamento do interior pela industrialização, a entrada e a difusão do taylorismo no país.

A importância de considerar a difusão e a gênese dessa forma de organização do trabalho consiste nas formas de organização social proposta pelos industriais, como desdobramento da racionalização do trabalho: a organização corporativa da sociedade e a conciliação de classes, assim como a cooptação da classe trabalhadora e a acomodação dos conflitos de classe.

Decorre da combinação entre o Simonsen "teórico" e condottiere, no sentido de capacidade de liderança do segmento industrialista, que nosso referencial teórico nos orienta a entender Simonsen como intelectual orgânico da fração de classe burguesa industrialista.

Entende-se o industrialismo a partir de sua contraposição aos interesses da fração de classe burguesa mercantil-agroexportadora. Os industrialistas, que estão entre os desenvolvimentistas do setor privado, são uma fração de classe da burguesia que defende um projeto de nação para o Brasil que envolve o desenvolvimento da indústria pesada e reivindica o apoio estatal para seu projeto. Assim, o projeto industrialista se choca de maneira frontal com os interesses da burguesia agroexportadora.

1 Consultar Draibe (1985). 
Não houve uma atuação relevante dos industriais no período de 1930 a 1964 pela via dos partidos políticos. Houve, isso sim, uma organização política dos industriais, em um primeiro momento, por fora da política institucional. Em um segundo momento, as reivindicações dos industriais diante do Estado os levam a organizações de grupos de fora do aparato estatal (caso da fundação da FiEsP, em 1928, por Simonsen e Matarazzo). Entretanto, os conflitos de classe e mesmo suas representações são cooptados para dentro do Estado pós-30, caracterizando a formação de um Estado demiurgo, atravessado de lado a lado pelos conflitos de classe, tanto introjetando esses conflitos quanto os mediando - o que levou fatalmente a uma autonomia formidável do Estado com relação às classes no período de 1930 a 1964.

Na década de 1920 viu-se surgir a primeira representação corporativa dos industriais - a FIESP, fundada em 1928 por Roberto Simonsen e Francisco Matarazzo -, mas foi apenas nos anos 1940 que o setor industrial conseguiu produzir um espaço de discussão sobre seus problemas e projetos maior que a representação sindical: os congressos econômicos do final do Governo Vargas.

\section{FORMAÇÃO DO ESTADO BRASILEIRO COMO PROCESSO CONFLITIVO E PROBLEMÁTICO}

Há na literatura econômica e histórica brasileira um extenso debate sobre o papel e os limites do planejamento e da intervenção do Estado na economia, em especial sobre a questão da industrialização (principalmente sobre a passagem do modelo mercantil-exportador para o modelo industrial). Embora haja inúmeras interpretações sobre a origem e o ritmo desse processo, é praticamente consenso a tese de que o planejamento conduzido pelo Estado foi peça importante e necessária, principalmente em função de nossa situação histórica de país de capitalismo tardio.

O Estado capitalista moderno em formação encontra sua gênese no Estado de Compromisso, que é fruto da crise agrária da República Velha (1889- 
1930), a qual encontrara seu fim na Revolução de 30. Entretanto, o quadro nesse momento é, além da crise do complexo cafeeiro, a falta de hegemonia, a dependência das classes médias com relação ao Estado e a pressão popular decorrente da crise econômica.

Nesse quadro, o Estado aparece como árbitro de interesses entre o capital e o trabalho, uma vez que aquela falta de hegemonia fez com que, nesse momento, o Estado se constituísse como autônomo em relação aos interesses dominantes. Draibe (1985, p. 22) chamou de via prussiana para o desenvolvimento a modernização conservadora, conduzida pelo Estado, manifestada no período.

Será em um campo fragmentado e heterogêneo, formado por diversidades de dentro e fora do Estado, na conjuntura das lutas políticas entre os setores históricos fundamentais (proletariado, burguesia mercantil e burguesia industrialista), que aparecerá a autonomia do Estado em relação à sociedade. O Estado aparece aqui como um reequilibrador de interesses. Entretanto, sua autonomia encontraria limitações.

A primeira delas reside no fato de que o Estado tinha sua autonomia orientada a hierarquizar os interesses sociais. O núcleo dirigente orientava a ação estatal, e essa orientação era direcionada pelas lutas travadas dentro do Estado, tais como na comissão de planejamento econômico - na controvérsia entre Simonsen (desenvolvimentismo do setor privado) e Eugênio Gudin (liberal, defensor da tese de "vocação agrária" da economia brasileira)². A partir daqui, pode-se inferir que a organização do Estado e suas relações com a sociedade passam a ter caráter fortemente corporativo, visto que o Estado absorve os conflitos sociais, para, em um segundo movimento, regulá-los. Draibe (1985, pp. 43-45) ressalta que a industrialização no Brasil implicou aquisição por parte do Estado de estruturas capitalistas.

2 Bielschowsky (2004, pp. 241-243). 


\section{O PENSAMENTO DE ROBERTO SIMONSEN}

Existe, atualmente, ampla bibliografia sobre Roberto Simonsen. Basicamente, duas abordagens principais: a que divide a obra do autor em fases de elaboração intelectual (VIEIRA, 1987; CEPÊDA, 2004; RompATto, 2004); e a que trata da obra como uma unidade contínua (MAZA, 2004; FANGaniello, 1970; CaEtano, 1994). Todos os estudos consideram as pretensões de Simonsen em torno da construção da nação. Todos destacam, em maior ou menor medida, a interpretação de Simonsen sobre o papel e o lugar da classe trabalhadora, cujas demandas deveriam parar de ser tratadas como mero "caso de polícia"; outrossim, englobadas no projeto político. Maza (2004), por exemplo, enfatiza de forma muito acentuada a interpretação de Simonsen a partir do mundo do trabalho e sugere que o central no pensamento simonseano seria uma pretensão à taylorização da sociedade. Fanganiello, por outro lado, enfatiza fortemente a unidade da obra. Para a autora, Simonsen foi um protecionista declarado, ao contrário de Amaro Cavalcanti, por exemplo. Foi claramente influenciado pelas ideias de Frederick List, assim como adepto da ideia de sistema econômico nacional.

Para Simonsen, a riqueza potencial não é riqueza, porque a ninguém beneficia. Assim, é necessário transformar as potencialidades em produção. Dessa maneira, riqueza e bem-estar dependeriam basicamente do trabalho e do progresso técnico (Fanganiello, 1970, pp. i-iii).

Mesmo Fanganiello já afirmava que Simonsen antecederia o pensamento desenvolvimentista das décadas seguintes. A ideologia industrialista de Simonsen consistiria principalmente na conciliação entre liberalismo e intervencionismo estatal, desdobrando-se na harmonização entre interesses públicos e privados. A engenharia condicionaria o pensamento de Roberto Simonsen, de modo a cristalizar no pensamento do autor a importância da técnica no benefício material e, portanto, espiritual da sociedade. 
Caetano corroboraria essa ideia, apontando que houve uma continuidade no pensamento de Roberto Simonsen, de modo a explicitar uma solidez e um sentido à sua obra. Roberto Simonsen, a partir dos anos 1910, instituiu a organização científica do trabalho como método de administração de suas empresas, de modo a estabelecer um controle social mais geral sobre os trabalhadores, a partir do modo de organização do trabalho; em uma dimensão mais estrita, o taylorismo como modo de organização do trabalho e regime de acumulação; em uma dimensão mais ampliada, a "cidade" como lugar da própria sociabilidade, lugar esse disciplinado e esquadrinhado.

A paz social e a ideia de "colaboração" corroboram essa ideologia, pela qual os trabalhadores estariam incluídos no sistema, de modo a ampliar o mercado interno e o controle dos movimentos sociais pela ordem social hegemônica. A religião cristã (em especial o catolicismo) entra como força valorativa da ética do trabalho e da família, instrumentos de controle social sobre a classe trabalhadora (CAETANO, 1994, pp. 275-276).

Assim, o industrialismo consistiu na ideologia que deu consistência intelectual a essa ordem de coisas, assim como se constituiu como um projeto político hegemônico e global. Seu locus por excelência foi o CIESP, e seu principal intelectual, Roberto Simonsen. Como projeto hegemônico, Caetano entende hegemonia - tal como Raymond Williams - como uma dimensão propriamente cultural de legitimação da ordem social dominante.

Assim é que, no discurso do empresariado, nota-se uma valorização do trabalhador nacional, com vistas ao compromisso entre as classes e ao crescimento do mercado interno de consumo. Por outro lado, essa inclusão da massa trabalhadora no sistema político brasileiro pós-1930 significou também uma inclusão elitista, no sentido de que propostas e projetos políticos de trabalhadores foram progressivamente marginalizados em prol da hegemonia industrialista/desenvolvimentista em gestação.

A “nação" entra aqui como a hierarquizadora de prioridades, sendo invocada a cada dificuldade - tácita ou em potencial - que a luta de classes poderia 
desencadear. As rearticulações de alianças que isolaram do poder as propostas da classe trabalhadora aconteceram essencialmente na Constituinte de 1932 e no Golpe do Estado Novo de 1937 (CAETAno, 1994, pp. 272-274).

O problema dessas abordagens que dão ênfase à unidade da obra é que elas não dão conta da elaboração do pensamento de Simonsen. Por se tratar de um autor de fases, cada uma possui tensões e questionamentos internos, de modo que, em um sentido geral, pode-se colocar o sentido dessa elaboração intelectual como a superação, no pensamento simonseano, da ambiguidade que sofre entre intervencionismo e liberalismo. Esse par de opostos foi tratado de maneiras diversas, de modo que um mapeamento é feito por outra corrente do debate (CEPÊDA, 2004; VIEIRA, 1987; ROMPATTO, 2004) e ele tende a fazer três marcações principais no pensamento de Simonsen.

Em uma primeira fase, os textos escritos entre 1912 e 1928 consistem fundamentalmente em textos de ordem técnica, entre os quais, sobre o calçamento de Santos e a construção de quartéis para o Exército. Existe, na primeira fase da obra, uma caracterização da organização científica do trabalho, claramente inspirada no taylorismo, em franca oposição aos métodos empiristas da época. Aqui já é evidente que Simonsen ambicionaria arquitetar um modelo de organização não apenas no mundo da produção, mas sim o conjunto amplo das relações econômicas da sociedade, em torno da racionalização do trabalho e do aumento da eficiência produtiva. O texto em destaque é $O$ Trabalho Moderno, de 1919. Os demais textos dessa fase foram reunidos em uma compilação (provavelmente) de 1932, À Margem da Profissão.

Na segunda fase, o pensamento de Simonsen e o projeto político subsequente avançam no processo de elaboração político-intelectual, em sentido gramsciano, nas relações de forças políticas (GrAMSCI, 1978, pp. 49-51). Alguns textos dessa fase são: As Crises no Brasil (1931a), As Finanças e a Indústria (1931b), À Margem da Profissão (1932?), Ordem Econômica, Padrão de Vida e Algumas Realidades Brasileiras (1934) e Aspectos da Política Econômica Nacional (1935). 
Simonsen acreditava que as crises nacionais eram decorrentes das crises de ordem econômica, relacionadas ao câmbio e à "saúde" da moeda. Entendia que o principal motivo para tais distúrbios era a inépcia dos tomadores de decisão com relação à política econômica. Nesse sentido, já apontava, nessa fase, a necessidade da figura do técnico em economia em acordo com o "homem de negócios”, tanto no entendimento dos problemas quanto nas tomadas de decisão. Mas, nessa fase, Simonsen ainda não havia resolvido aquela esquizofrenia intelectual entre liberalismo e intervencionismo. Ao passo que julgava que o Estado deveria proteger a indústria nacional e manter boas taxas de câmbio, também argumentava pela inépcia dos governantes.

Pode-se dizer que a terceira fase da obra de Simonsen entra em uma gradual transição entre o texto de 1937, História Econômica do Brasil (150o1820), e Ensaios Sociais, Políticos e Econômicos, de 1943; essa fase, iniciada definitivamente em 1943, estender-se-á até a morte de Simonsen em 1948, quando publicou O Plano Marshall e um Novo Critério nas Relações Internacionais. Simonsen se descola do liberalismo e resolve aquela contradição de que padece seu pensamento. Em História Econômica, Simonsen faz um mapeamento e a sistematização do processo de formação econômica do Brasil colônia. Esse texto foi sistematizado a partir de suas aulas na Escola Livre de Sociologia e Política de São Paulo. Consistiu em um levantamento de dados, assim como uma rica interpretação deles. Ele argumentou pela necessidade de cruzar diferentes ciências sociais e humanas na compreensão do processo histórico, político e econômico brasileiro (Sociologia, Economia, Geografia, História). São dessa fase também Ensaios Sociais, Políticos e Econômicos (1943), A Evolução Industrial do Brasil (1939) e os pareceres submetidos ao CNPIC e CPE, nos quais esteve em Controvérsia com Eugenio Gudin.

Foi Vera Cepêda (2004, p. 322) quem percebeu que a relação entre a crítica de Simonsen ao plano Marshall e o conjunto dos textos em que ele fez a defesa do planejamento antecipou o pensamento cepalino em sua essência. 
De acordo com a autora, a ligação entre os textos de Simonsen sobre planejamento e a crítica ao plano Marshall levou a uma antecipação de todos os argumentos cepalinos. Para Simonsen, uma vez que a posição dos diferentes países é desigual em termos de capacidade produtiva e tecnológica, há uma clivagem entre países supercapitalizados (produtores industriais) e subcapitalizados (agroexportadores). As trocas são desiguais, uma vez que a natureza da produção determina o valor agregado e, portanto, os termos de troca.

A tendência ao monopólio pelos países supercapitalizados, juntamente com a especialização das economias nacionais, dentro da divisão internacional do trabalho, leva ao aprofundamento dessa dependência. O escape para esse círculo vicioso seria um crescimento "para fora", no sentido de abandono das teses liberais ortodoxas do livre-cambismo nas trocas internacionais; e "para dentro", no sentido de adotar o planejamento econômico como método, com vistas a organizar e disciplinar as forças produtivas e, com isso, atingir o desenvolvimento econômico e social (CEPÊDA, 2004, pp. 322-323).

Além disso, há um consenso na literatura especializada quanto à influência que List e Manoilesco exerceram no pensamento de Simonsen.

De acordo com F. W. List, diferentes países têm diferentes trajetórias históricas, de modo que o desenvolvimento da indústria na Alemanha do século XIX não poderia acontecer sem o protecionismo, condição absolutamente temporária, enquanto a indústria nacional não pudesse competir em condições razoáveis com o mercado internacional. Simonsen defenderia que o Estado brasileiro deveria proteger a incipiente indústria nacional enquanto ela não pudesse concorrer vis-à-vis com a grande indústria dos países centrais. Deveria o Estado promover políticas industriais de incentivo à inovação e ao desenvolvimento tecnológico.

Manoilesco foi, à época, o autor referencial ao que toca a doutrina corporativista de organização do Estado e da sociedade. O corporativismo consistia na “doutrina da organização funcional da nação, enquanto as corporações são os órgãos que executam essas funções" (ManolLESco, 1938, p. 50). 
A corporação seria definida pela função nacional que ela exerce dentro da sociedade nacional, a qual consistiria em um conjunto orgânico de corporações. Dois desdobramentos dessa ideia seriam: primeiramente, o reconhecimento da existência concreta do indivíduo, ainda que subalterna ao Estado, uma vez que, no corporativismo (e de maneira diametralmente oposta ao liberalismo), o indivíduo não tem direitos, mas sim deveres e está hierarquicamente subordinado à coletividade; em segundo lugar, a centralidade que a doutrina corporativista atribui à personalidade coletiva, em detrimento da atomização individualista da sociedade moderna e liberal.

Decorre dessa centralidade a soberania do Estado corporativista. Para Manoilesco, o Estado é a expressão máxima da coletividade nacional. Assim, é o Estado que engloba a sociedade nacional, e não o contrário, como poderiam sugerir os contratualistas, por exemplo.

Dessa maneira é que, para Manoilesco, a finalidade (se bem poderia dizer que "finalidade" fosse propriedade de tal Estado) do Estado corporativista é o próprio desenvolvimento da nação. Assim é que o autor romeno sugere que a concepção pela qual o Estado seja neutro ou mesmo "agnóstico" é falsa, uma vez que o próprio Estado, ele mesmo, é a encarnação de um ideal. Mesmo a sociedade nacional para Manoilesco consistiria em um conjunto coletivo de indivíduos que compartilham os mesmos ideais, o que faz da participação deles na grande corporação, de certa forma, voluntária.

A existência da corporação e, por consequência, do Estado supera em importância a existência individual (Manollesco, 1938, p. 48). Heterogênea em sua composição, a corporação é homogênea em sua finalidade.

Dentro da sociedade nacional, as corporações são formadas de acordo com a função nacional que desempenham; função industrial, por exemplo. Entretanto, Manoilesco argumenta que esse tipo de organização social não pode ser confundido com a mera representação profissional parlamentar, porque a doutrina do corporativismo consiste em uma forma de organização completa da sociedade, ultrapassando o âmbito meramente econômico. São 
notáveis, portanto, os elementos da paz social e da concepção orgânica da sociedade no pensamento de Manoilesco. Esses dois elementos primordiais foram decisivos também no pensamento de Roberto Simonsen.

\section{O I CONGRESSO BRASILEIRO DE ECONOMIA}

O I Congresso Brasileiro da Indústria foi realizado entre 25 de novembro e 18 de dezembro de 1943, na então capital federal, organizado pela Confederação Nacional do Comércio (CNC), dentro da sede social da Associação Comercial do Rio de Janeiro.

Getúlio Vargas foi o presidente de honra; João Daundt d'Oliveira - presidente da Federação de Associações Comerciais do Brasil e da Associação Comercial do Rio - foi o presidente efetivo; Euvaldo Lodi - presidente da Confederação Nacional da Indústria - foi o vice-presidente do Congresso. A direção técnica ficou a cargo do Instituto de Economia da Associação Comercial do Rio de Janeiro, na pessoa de seu presidente, Daniel de Carvalho, e de seus membros: Alde Feijó Sampaio, Eduardo Lopes Rodrigues, Eugênio Gudin, Euvaldo Lodi, Gastão Vidigal, Gileno de Carli, José Lourdes Salgado Scarpa, Luiz Simões Lopes, Mário Augusto Teixeira de Freitas, Mário Brant, Napoleão de Alencastro Guimarães, Otávio Gouvêa de Bulhões, Roberto Simonsen, assim como de seu secretário-geral, Luiz Dodsworth Martins.

Os anais do Congresso foram publicados em três volumes (o primeiro, em 1943, o segundo, em 1944, e o terceiro, em 1946) pela Associação Comercial do Rio de Janeiro. O primeiro volume (de 198 páginas) apresenta os discursos solenes de abertura e encerramento, o programa preliminar do Congresso, a relação dos membros e das entidades, o regimento, as comissões e as teses apresentadas. O segundo volume (de 635 páginas) contém os trabalhos da comissão de redação e das sessões no Plenário. O terceiro volume (de 872 páginas) é dividido em duas partes: na primeira apresenta as teses da comissão 
de produção agrícola e industrial; na segunda, da comissão de circulação e transportes.

\section{A COMISSÃO DE PRODUÇÃO AGRÍCOLA E INDUSTRIAL}

Roberto Simonsen era o presidente da I Comissão; Luiz Siegman, seu vice-presidente; e seu secretário, Paulo Eleutério. As discussões começam no âmbito da matriz energética (J. Pires do Rio, Edgard Teixeira Leite, José Ermírio de Moraes, Luiz Siegman, Antônio Augusto de Barros Penteado, João Cleophas, Cosme Valentini, Américo Mello), passando para a discussão sobre a colonização industrial do interior (Luiz de Rollemberg, Militino C. Rosa, Antenor Rangel filho, Francisco Jardim, Hugo Carneiro, Irineu Bornhansen, João Costa Palmeira, Paulo Eleutério, Virgilio de Sousa e Creso Braga); em seguida, a discussão passou para as preocupações em torno da questão agrária propriamente (J. Carneiro de Rezende, Rômulo Cavina, Gileno de Carli, Abelardo Villas-Boas, Paulo Eleutério, Heitor Grillo, João Cleophas, Edgard Teixeira Leite); e, por último, a preocupação com o planejamento econômico e a organização do trabalho (Aldo Azevedo, Charles Augusto Nobile, Luiz Sayão de Faria, Fausto Maia, Virgílio Lucas, Rubem Roquette).

O objetivo desta seção será examinar algumas teses mais importantes discutidas na Comissão, que, por vários motivos, é a mais importante do Congresso. A presença de Roberto Simonsen denota o exercício de (ou tentativa de) direção política, intelectual e moral em um espaço de poder sui generis, considerando a consolidação ideológica do pensamento industrialista, assim como as tomadas de decisão que esse processo poderia afetar. E aqui será possível, portanto, medir até que ponto o pensamento médio dos industriais estava afinado com a ideologia forjada no pensamento da direção do movimento.

De acordo com o Parágrafo Único do art. 8 do Regimento do Congresso, “O Presidente e o Vice-Presidente de cada Comissão serão eleitos por seus 
pares, sendo que o presidente escolherá entre eles seu respectivo secretário" (Congresso Brasileiro de Economia, 1943, v. 1, p. 54), de modo que a posição de Simonsen dentro da presidência da Comissão é um sinal significativo de liderança política entre os industriais.

Os temas discutidos e os debates prolongados e profícuos, assim como a relevância dessas agendas para o Congresso, mostram a importância da II Comissão. Também é onde as pautas são mais extensas, salvo a exceção de debates similares ou iguais em outras comissões - caso da Comissão VI (a colonização do interior) e VII (a questão da renda salarial e da alimentação).

Com relação aos problemas apresentados pela matriz energética, um dos principais pontos de estrangulamento da economia brasileira da época, os industriais parecem ter certo consenso com relação à causa e à solução do problema. País de amplas possibilidades de resolução natural desse estrangulamento, padece, no entanto, de deficiente potencial de investimento em infraestrutura na área energética, e isso decorre - de acordo com os industriais - do Código de Águas e Minas vigente. Necessário seria, portanto, alterar esse Código com vistas à entrada do capital estrangeiro quando necessário, seja como investidor, rentista, seja como sócio; idem no caso dos combustíveis (gasolina, hulha, turfa e álcool).

Desde sempre estão recomendados, no I Congresso Brasileiro de Economia, estudos sobre a geografia econômica do território. Isso porque os industriais tendiam a sugerir que o hinterland ou era desabitado ou habitado por populações "alienígenas" (nativas, indígenas) que precisavam ser integradas à civilização industrial moderna. Nesse ponto, concordavam com o argumento liberal da época - notadamente gudiniano - de que o país padecia de escassez de mão de obra, daí a defesa dos industriais ao que chamavam de “imigração selecionada de técnicos e trabalhadores".

Diferentemente dos liberais - que usavam do argumento da escassez de braços para atacar o planejamento econômico e reforçar a lei das vantagens comparativas ricardianas -, o industrialismo colocava na conta do plane- 
Comissão I. Questão energética.

\begin{tabular}{|c|c|c|c|}
\hline Autor & Título da Tese & Proposta da Tese & $\begin{array}{c}\text { Parecer } \\
\text { (Parecerista) }\end{array}$ \\
\hline J. Pires do Rio & $\begin{array}{l}\text { "Observações } \\
\text { sobre o } \\
\text { aproveitamento } \\
\text { dos recursos } \\
\text { naturais do país" }\end{array}$ & $\begin{array}{l}\text { Diante do } \\
\text { estrangulamento } \\
\text { energético, o autor } \\
\text { propôs aguardar as } \\
\text { pesquisas de carvão } \\
\text { mineral em Volta } \\
\text { Redonda. }\end{array}$ & $\begin{array}{l}\text { Recusada (Edgar } \\
\text { Teixeira Leite) }\end{array}$ \\
\hline $\begin{array}{l}\text { J. Erminio de } \\
\text { Moraes }\end{array}$ & $\begin{array}{l}\text { “Combustíveis e } \\
\text { industrialização" }\end{array}$ & $\begin{array}{l}\text { Mudar o código de } \\
\text { águas, a fim de permitir } \\
\text { a entrada do capital } \\
\text { estrangeiro no setor de } \\
\text { minas e energia. }\end{array}$ & $\begin{array}{l}\text { Recomendada } \\
\text { (Luiz Siegman) }\end{array}$ \\
\hline $\begin{array}{l}\text { Antonio Augusto } \\
\text { de Barros } \\
\text { Penteado }\end{array}$ & $\begin{array}{l}\text { "Estudo dos } \\
\text { dispositivos legais } \\
\text { quanto ao melhor } \\
\text { aproveitamento } \\
\text { dos recursos } \\
\text { naturais do país" }\end{array}$ & $\begin{array}{l}\text { Por causa do alto custo } \\
\text { de aproveitamento do } \\
\text { potencial energético, } \\
\text { em particular as quedas } \\
\text { d'água, sugere mudança } \\
\text { no Código de Águas, } \\
\text { a fim de permitir a } \\
\text { sociedade em empresas } \\
\text { entre capital nacional e } \\
\text { estrangeiro. }\end{array}$ & $\begin{array}{l}\text { Recomendada } \\
\text { (João Cleophas) }\end{array}$ \\
\hline Cosme Valentini & $\begin{array}{l}\text { "As nossas turfas } \\
\text { e a economia } \\
\text { nacional" }\end{array}$ & $\begin{array}{l}\text { Colonização industrial } \\
\text { do interior do país, } \\
\text { pautada nos estudos de } \\
\text { geografia econômica, } \\
\text { com vistas à exploração } \\
\text { da turfa. }\end{array}$ & $\begin{array}{l}\text { Recomendada } \\
\text { (Luiz Siegman) }\end{array}$ \\
\hline Américo Mello & $\begin{array}{l}\text { "Cachoeira de } \\
\text { Paulo Afonso" }\end{array}$ & $\begin{array}{l}\text { Defendeu a construção } \\
\text { de uma usina } \\
\text { hidrelétrica em Paulo } \\
\text { Afonso/AL, construída } \\
\text { com capital privado e } \\
\text { público (e estrangeiro, } \\
\text { se necessário). }\end{array}$ & $\begin{array}{l}\text { Recomendada } \\
\text { (João Cleophas) }\end{array}$ \\
\hline $\begin{array}{l}\text { Militino Rosa, } \\
\text { Antenor Rangel } \\
\text { Filho }\end{array}$ & $\begin{array}{l}\text { "Os subprodutos } \\
\text { de destilação da } \\
\text { hulha" }\end{array}$ & $\begin{array}{l}\text { Reivindicou do Estado } \\
\text { incentivo à produção da } \\
\text { hulha e seus derivados, } \\
\text { assim como uma lei } \\
\text { anti-dumping, como } \\
\text { solução (parcial, embora } \\
\text { importante) para } \\
\text { o estrangulamento } \\
\text { energético. }\end{array}$ & $\begin{array}{l}\text { Recomendada } \\
\text { (Irineu } \\
\text { Bornhansen) }\end{array}$ \\
\hline
\end{tabular}


jamento econômico a imigração selecionada. Sem imigração de técnicos e professores, assim como de concessão de bolsas de estudos no exterior para os estudantes brasileiros, o crescimento econômico planejado e acelerado estaria comprometido.

A imigração e a colonização do interior formam as duas faces da medalha da industrialização induzida. O eixo dessa colonização muda: em vez de braços para a agricultura, vêm técnicos, cientistas e operários para uma colonização industrial do interior do país, orientada pelos estudos de geografia econômica. Notadamente, a hulha, a turfa e o petróleo têm proeminência na rota da nova colonização. E como, de acordo com o pensamento industrialista, indústria é civilização e progresso, resolver-se-ia o problema do atraso do Brasil rural, assim como "civilizar-se-ia” o hinterland. Mas, além de civilização e riqueza, ao agregar valor, a indústria faz com que a economia cresça e a nação se construa.

Entretanto, uma leitura das teses defendidas tanto na I Comissão quanto no decorrer do Congresso mostra pontos sérios de descontinuidade. Por mais de uma vez os industriais foram vacilantes com relação à equiparação de direitos entre trabalhadores urbanos e rurais, assim como chegaram a supor seriamente que o trabalhador do campo não merecia um piso salarial. A tese da indolência do trabalhador brasileiro também fez emergir constrangedoras dúvidas entre os industriais e significou sério hiato com relação ao pensamento da direção industrialista.

Tanto Simonsen quanto Lodi e Daundt D’Oliveira argumentaram mais de uma vez que os direitos sociais dos trabalhadores consistiam em elemento crucial em uma concepção corporativista de sociedade. Entretanto, o corporativismo pretensamente hegemônico da direção industrialista encontrou um sério obstáculo na base. Isso porque a média dos industriais era muito resistente a ceder qualquer parte dos seus dividendos aos direitos sociais dos trabalhadores.

O planejamento, combinado com o projeto de crescimento acelerado e colonização do hinterland, desembocava na questão nacional. Isso porque 
estavam também em jogo alternativas de projetos de futuro para a sociedade, assim como a própria construção da nação. Apesar de clara para a direção do movimento industrialista, ainda mais para Simonsen, essa reflexão dificilmente aparece no pensamento da base. Entretanto, outro elemento (é possível sugerir que igualmente importante) aparece triunfante no pensamento médio dos industriais no Congresso de Economia: a necessidade da difusão da organização científica do trabalho, o taylorismo.

A OCT, como eles denominavam, era uma peça importante do quebra-cabeça, porque desempenhava a função de aumentar a produtividade e, consequentemente, de gerar renda e capital, assim como criar uma demanda efetiva interna, que aumenta a produtividade, e assim por diante.

Apesar de pretensiosos, nota-se a dependência completa dos industriais com relação ao Estado, no que se refere a suas realizações. É que, junto com a construção do ator político, vem a definição por seu locus social, e aí entra o Estado e também a nação. Isso porque, concomitantemente ao ganho de importância dos industriais na cena econômica, vêm novas necessidades trazidas por esse grupo social. E aí entra um novo princípio de hierarquização de prioridades: a indústria concorre ao desenvolvimento da nação. Mas o que deveria ser uma mostra de elaboração intelectual do segmento industrialista acaba se mostrando sério ponto de descontinuidade entre direção e base do movimento industrialista. Isso porque, enquanto para Simonsen o "Homem de Empresa" é o maestro que rege essa complexa sinfonia do desenvolvimento, ocupando, portanto, postos de decisão no Estado, para a média dos industriais, o Estado é um assistente para seus negócios.

Ainda aqui a elaboração político-intelectual seria exitosa. Durante as discussões na Comissão de Redação, surgiria um importante consenso entre os industriais em torno de seu protagonismo na tomada de decisões dentro do Estado, embora nas Comissões Técnicas esse argumento ainda estivesse nebuloso entre os industriais. 
Comissão I. Planejamento, colonização e taylorismo.

\begin{tabular}{|c|c|c|c|}
\hline Autor & Título da Tese & Proposta da Tese & Parecer (Relator) \\
\hline $\begin{array}{l}\text { Paulo } \\
\text { Eleutério }\end{array}$ & $\begin{array}{l}\text { "Orientação } \\
\text { administrativa } \\
\text { para o } \\
\text { aproveitamento } \\
\text { da economia } \\
\text { nacional" }\end{array}$ & $\begin{array}{l}\text { Sugeriu a criação de um } \\
\text { Ministério da Economia } \\
\text { Nacional, que centralizaria } \\
\text { o crescimento econômico } \\
\text { planejado e acelerado. }\end{array}$ & $\begin{array}{l}\text { Recomendada (Hugo } \\
\text { Carneiro) }\end{array}$ \\
\hline Aldo Azevedo & $\begin{array}{l}\text { "Desenvolvimento } \\
\text { industrial do } \\
\text { Brasil e seus } \\
\text { problemas" }\end{array}$ & $\begin{array}{l}\text { Defendeu fortemente o } \\
\text { treinamento em bases } \\
\text { tayloristas dos diretores } \\
\text { e gerentes das empresas, } \\
\text { assim como a difusão do } \\
\text { ensino técnico. } \\
\text { Argumentou a } \\
\text { interiorização das } \\
\text { populações em dois } \\
\text { processos simultâneos: } \\
\text { fornecimento de crédito } \\
\text { a esses empreendedores, } \\
\text { via bancos industriais; } \\
\text { interiorização planejada a } \\
\text { partir de um órgão misto } \\
\text { público/privado. } \\
\text { Sugeria que a figura do } \\
\text { colono era, ela mesma, a } \\
\text { de um novo empresário. }\end{array}$ & $\begin{array}{l}\text { Recomendada } \\
\text { (Charles Augusto } \\
\text { Nobili) }\end{array}$ \\
\hline $\begin{array}{l}\text { Armando } \\
\text { Godoy Filho }\end{array}$ & $\begin{array}{l}\text { "Economia } \\
\text { como base de } \\
\text { civilização no } \\
\text { oeste brasileiro" }\end{array}$ & $\begin{array}{l}\text { Cabe à indústria } \\
\text { função civilizatória na } \\
\text { colonização do interior. } \\
\text { Assim, deve o Estado } \\
\text { criar condições a tal } \\
\text { processo, fornecendo bens } \\
\text { públicos notadamente } \\
\text { do setor de transportes } \\
\text { (especialmente ferrovias). }\end{array}$ & $\begin{array}{l}\text { Recomendada } \\
\text { (Heitor Grillo) }\end{array}$ \\
\hline $\begin{array}{l}\text { Luiz Sayão } \\
\text { de Faria }\end{array}$ & $\begin{array}{l}\text { "Assistência } \\
\text { econômica } \\
\text { às indústrias } \\
\text { básicas" }\end{array}$ & $\begin{array}{l}\text { Com relação à indústria } \\
\text { pesada, deve o Estado } \\
\text { dar assistência técnica e } \\
\text { creditícia a esse segmento. }\end{array}$ & $\begin{array}{l}\text { Recomendada } \\
\text { (Fausto Maia) }\end{array}$ \\
\hline
\end{tabular}

Outro ponto nebuloso certamente foi a questão agrária. Apesar de reconhecer que a indústria e a agricultura tendiam a formar uma unidade dinâmica no conjunto da economia nacional, não tendiam a pensar que o rural e o urbano 
pudessem ser uma sociedade. Há aqui uma demonstração muito interessante de consciência compósita: campo e cidade devem constituir uma economia, mas duas sociedades. Isso porque os industriais não queriam garantir os direitos sociais do trabalhador rural nesse momento, provavelmente porque queriam ganhar o apoio das agriculturas satélites com relação a café (maniçoba, açúcar, algodão, babaçu, látex), que estavam marginalizadas no sistema político, mas que figuravam notadamente no Congresso.

Era um ponto crítico sem dúvida, mas que não comprometia decisivamente a direção político-intelectual de Simonsen sobre o segmento industrialista, e isso porque eles concordavam em um ponto interessante, chamado colonização industrial do hinterland. No final das contas, o pensamento industrial brasileiro tendia a pensar de maneira dualista-estrutural: era necessária a vitória do moderno-urbano-industrial sobre o arcaico-rural-semifeudal.

E o círculo se fecha quando se olha para as teses defendidas tanto por entidades quanto por personalidades do campo que figuraram no Congresso de 1943: todas as teses invocam a taylorização e "modernização" da agricultura - à exceção da tese de Luiz de Souza Melo, rejeitada por sugerir que o eixo do desenvolvimento econômico no pós-guerra poderia ser a agricultura. A consolidação do projeto industrialista está em curso para superar sua dimensão meramente econômico-corporativa.

Curiosamente, tanto os industriais quanto os representantes da agricultura no Congresso foram a favor de uma proposta de reforma agrária. Esse ponto demonstra fortemente que a relação de forças políticas se ampliou na dimensão econômico-corporativa para o grupo social mais amplo, uma vez que frações de classe burguesas da indústria estabeleceram aliança com frações de classe da burguesia agrária, mas essa relação ainda não amadureceria para um âmbito político global e pretensamente hegemônico, porque ainda não se buscavam alianças com os trabalhadores. 
Comissão I. Questão agrária.

\begin{tabular}{|c|c|c|c|}
\hline Autor & Título da Tese & Proposta da Tese & Parecer (Relator) \\
\hline $\begin{array}{l}\text { Abelardo } \\
\text { Villas-Bôas }\end{array}$ & $\begin{array}{l}\text { "Elementos técnicos } \\
\text { e econômicos para } \\
\text { a organização da } \\
\text { agricultura" }\end{array}$ & $\begin{array}{l}\text { Taylorização da } \\
\text { agricultura. }\end{array}$ & $\begin{array}{l}\text { Recomendada } \\
\text { (Paulo Eleutério) }\end{array}$ \\
\hline João Cleophas & $\begin{array}{l}\text { "Organização da } \\
\text { agricultura no } \\
\text { Nordeste brasileiro" }\end{array}$ & $\begin{array}{l}\text { Reconheceu a forte perda } \\
\text { em termos de trocas } \\
\text { com relação aos gêneros } \\
\text { agrícolas, assim como } \\
\text { a produtividade nos } \\
\text { segmentos que atendiam } \\
\text { o mercado interno. } \\
\text { Recomendou fortemente } \\
\text { a taylorização da } \\
\text { agricultura como solução } \\
\text { ao impasse. } \\
\text { Rejeitou a } \\
\text { regulamentação dos } \\
\text { direitos sociais rurais por } \\
\text { julgar desnecessário, o } \\
\text { que poderia reforçar a } \\
\text { natureza “indolente” do } \\
\text { trabalhador rural. }\end{array}$ & $\begin{array}{l}\text { Recomendada } \\
\text { (Edgar Teixeira } \\
\text { Leite) }\end{array}$ \\
\hline $\begin{array}{l}\text { J. Carneiro de } \\
\text { Rezende. }\end{array}$ & $\begin{array}{l}\text { "Parcelamento } \\
\text { das grandes } \\
\text { propriedades" }\end{array}$ & $\begin{array}{l}\text { Defendia a expropriação } \\
\text { e divisão de grandes } \\
\text { propriedades rurais e } \\
\text { improdutivas. Defendia } \\
\text { a concessão de linhas de } \\
\text { crédito especiais para os } \\
\text { pequenos proprietários } \\
\text { rurais, assim como } \\
\text { assistência técnica na } \\
\text { implantação da Ост. }\end{array}$ & $\begin{array}{l}\text { Recomendada } \\
\text { (Rômulo Cavina, } \\
\text { Gileno de Carli) }\end{array}$ \\
\hline $\begin{array}{l}\text { Luiz de Sousa } \\
\text { Melo }\end{array}$ & $\begin{array}{l}\text { "Lineamento de } \\
\text { estruturação } \\
\text { econômica" }\end{array}$ & $\begin{array}{l}\text { Argumentou que a } \\
\text { economia agrária é o } \\
\text { alicerce da reconstrução } \\
\text { econômica no pós-guerra. } \\
\text { Sugere a criação de um } \\
\text { "direito rural". }\end{array}$ & $\begin{array}{l}\text { Rejeitada } \\
\text { (Edgard Teixeira } \\
\text { Leite) }\end{array}$ \\
\hline
\end{tabular}

Nesse ponto, certamente os industriais trouxeram para essa relação de forças políticas os trabalhadores urbanos, prova de que o projeto SENAFI e depois SEnAI e SESI de 1945, assim como o apoio aos direitos sociais do 
trabalhador urbano, denota essa expansão. Entretanto, encontrava sérias dificuldades com os trabalhadores rurais. Também - e isso em todos os níveis - a persistência de uma concepção dualista estrutural no pensamento industrial mostra quão frágil era a aliança entre frações de classe da burguesia.

Mas não era a questão agrária o cimento ideológico do Congresso e desses atores que estão se construindo. Juntamente com a construção desses atores, amadurece-se a consciência política deles, de modo que se ampliam e se tornam mais complexas as relações de forças políticas entre eles. É por isso que a questão nacional é que dá formas nítidas e precisas tanto a esse conjunto de relações quanto à ideologia que se consolida juntamente com a efetivação desses atores em suas posições sociais e com tudo o que isso implica: um conjunto de significados, de hierarquização de prioridades e de novas demandas e, portanto, projetos. Decorre disso que a consolidação do projeto industrialista causa e é causada pela consolidação do próprio segmento industrial diante do processo (problemático) de modernização da sociedade brasileira. Quanto mais inserto for o industrial no conjunto social, maior também será a complexidade da organização de interesses desse segmento.

\section{SIMONSEN VERSUS GUDIN: DEBATES NA COMISSÃO DE REDAÇÃO}

As discussões diretas entre Eugênio Gudin e Roberto Simonsen nas sessões do Plenário do I Congresso Brasileiro de Economia de 1943 ocorreram na quarta sessão - de 16 de dezembro, às nove horas.

Foram dois os principais pontos discutidos nessa fase do debate: a questão da necessidade de um Banco Central e o tratamento que se deveria dar à inflação.

Simonsen entendia que o Banco Central deveria ser um órgão coordenador da economia nacional e a serviço do desenvolvimento econômico, assim como sua direção deveria ser composta tanto por economistas profissionais, como por homens de letras e empresários. O Banco Central coordenaria a 
economia de modo a controlar os fluxos monetários, de forma a "drenar" o capital para os elos fracos da economia. Gudin defendia que entre os tomadores de decisão de um Banco Central estariam representados diversos setores da elite, mas discordava das finalidades do Banco, segundo Simonsen. Apesar de concordar acerca de que o Banco Central teria a função de coordenador da economia, a prioridade seria garantir a liquidez do sistema bancário, e não fortalecer setores da economia que não gerassem vantagens comparativas.

Com relação à inflação, Gudin entendia - como monetarista - que ela seria causada pelo excesso de pagamentos em circulação. Assim, seria necessário "enxugar" a economia por meio de medidas taxativas e compensatórias. Simonsen concordava com essa argumentação até nesse ponto, mas defendia que os industriais tivessem a opção de comprar ou não títulos da dívida pública e bônus, voluntariamente. Ao bem dizer, é duvidoso que Simonsen chamasse exatamente aquela conjuntura de "inflação", porque para ele não eram os preços que eram altos, mas sim os salários que eram baixos, e isso em decorrência das pesadas assimetrias nas trocas internacionais.

Mas o ponto crítico realmente era: o que fazer com esses excedentes? Simonsen e Gudin concordavam sobre ser uma oportunidade ímpar de conseguir importar tecnologia e bens de capital. Fossem impostos ou bônus da dívida pública, estariam ancorados em letras de exportação. Aqui eles caíram em outra questão: quem operaria o sistema? Pode-se argumentar que era duvidoso que Gudin viesse a cumprir a promessa de pôr em andamento uma política industrial, porque ele havia escrito mais de uma vez que era melhor queimar o excedente inflacionário do que colocá-lo novamente em circulação. Por outro lado, seria necessário um mecanismo de freios e contrapesos para garantir que o setor privado, completamente livre, não praticasse com o excedente gasto suntuário no exterior.

Mas a questão não se resolveu no Congresso. A agenda teria de ser votada. Gudin propôs duas fórmulas para superar o problema da inflação: 
a) oferta de títulos compensatórios às empresas de capital excedente, em troca da absorção desse excedente monetário, proposta pela Comissão de Redação;

b) emissão de títulos ou depósitos especiais, também vinculados à importação, proposta pela III Comissão Técnica.

As duas propostas duelaram nas vozes de Simonsen, Alde Sampaio, Gudin, Pires Ferreira e Rodrigues: os três últimos alegaram preferência à comissão técnica e defenderam o primado da segunda proposta (b); enquanto Simonsen e Alde Sampaio invocam a "hierarquia" do Congresso, reivindicando preferência da tomada de decisão pela Comissão de Redação; João Daundt d'Oliveira, presidindo a sessão, deu preferência a Simonsen e colocou o item em votação. Com a oposição de Rodrigues, Hugo Hamann e Gudin (simbólica, pois, à exceção de Gudin, pertenciam à III Comissão Técnica, e não à Comissão de Redação $0^{3}$ ), a conclusão foi aprovada em Plenário.

Esse desenlace dos acontecimentos fez com que Simonsen "abortasse" um debate interessante sobre a inflação, porque sua proposta ganhou pela hierarquia do Congresso, e não pelos meios “normais" da argumentação e do convencimento do Plenário.

\section{CONCLUSÕES APROVADAS EM PLENÁRIO}

Embora o projeto industrialista de sociedade não fosse um projeto fechado, mesmo porque nesse caso o próprio ator é quem estava em construção,

3 (Congresso Brasileiro de Economia, 1, 1943, Tomo I, pp. 33-39.) A Comissão de Redação foi presidida por Euvaldo Lodi, e foram seus membros: Daniel de Carvalho (vice-presidente), Raul Jobim Bittencourt (secretário), Artur Torres, Dulphe Pinheiro Machado, Eugênio Gudin, José Augusto Bezerra de Medeiros, Mario Ludolf e Roberto Simonsen, além de uma Comissão Central de Cooperação e de assessores das Comissões Técnicas. Esses assessores variavam de dois a quatro por Comissão. Pela Comissão presidida por Gudin (III Comissão: Moeda e Bancos) estavam Alarico de Almeida Áreas e João Soares Neves, os quais - ao que consta nas atas - votaram junto com Simonsen. 
no I Congresso Brasileiro de Economia, ele ganhou esboços bastante nítidos. Os contornos desses esboços podem ser vistos pelas conclusões apresentadas por comissão.

- Comissão I - Produção Agrícola e Industrial: Recomendou a intensificação das pesquisas em fontes de energia (hulha, turfa, petróleo e energia hidroelétrica), a taylorização das empresas, a colonização industrial do hinterland e a compra do excedente agrícola. Além disso, recomendou a taylorização da exploração de culturas nativas como o látex e o parcelamento de grandes propriedades rurais improdutivas.

- Comissão II - Circulação e Transportes: Recomendou a desburocratização no sistema de transportes de mercadorias, assim como o abatimento de tarifas de circulação interna. Sugeriu a nacionalização da legislação de transportes.

- Comissão III - Moedas e Bancos: Propôs a taxação dos excedentes financeiros para o combate à inflação e a criação de um Banco Central, cuja principal função seria coordenar a economia e o fluxo financeiro.

- Comissão IV - Investimentos: Defendeu a presença do capital estrangeiro, o câmbio livre e uma Bolsa de Valores para todos os grandes centros urbanos, dentro de um sistema nacional de bolsas.

- Comissão V - Finanças Públicas: Recomendou a eliminação ou mesmo a redução da taxação sobre os lucros e o equilíbrio na arrecadação entre União, estados e municípios.

- Comissão VI - Planos Internacionais e de Caráter Social: Reconheceu a necessidade da criação imediata de uma comissão oficial encarregada da economia mundial no pós-guerra e reconheceu a necessidade de uma declaração de direitos de ordem econômica. Recomendou a permanente participação do Brasil na Organização Internacional do Trabalho (OIT) e a proibição da formação de trustes. Recomendou estudos para a formação de um banco pan-americano e a intensificação da indústria aurífera. 
- Comissão VII - Pesquisas e estudos econômicos: Considerou a importância da estatística nos estudos de problemas nacionais, assim como a importância da ação do IBGE. Recomendou que as empresas agrícolas, comerciais e industriais organizassem serviços de estatística. Recomendou aos poderes públicos desenvolver pesquisas para o estudo do problema da fome. Recomendou a criação do "curso superior em administração e finanças”, a concessão de bolsas de estudo no exterior e a regulamentação da profissão de economista.

- Comissão VIII - Atividades Econômicas do Estado: Deveriam ser as atividades do Estado, em regra, supletivas e orientadoras. A ação do Estado deveria sempre ocorrer depois de ouvidas as associações de classe. Considerou que não há incompatibilidade entre democracia e intervenção do Estado na economia, assim como considerou que a iniciativa dos indivíduos sempre foi a principal fonte de riqueza, e, por isso, a ação do Estado entra apenas na falta dela.

\section{CONSIDERAÇÕES FINAIS}

Embora o projeto industrialista não fosse algo fechado (e por que não dizer coeso), apresentou um esboço bastante nítido com relação ao projeto nacional decorrente da ideologia industrialista, ela mesma em constante formação e transformação. Destaca-se nesse processo Roberto Simonsen como intelectual orgânico do segmento industrialista e liderança política do segmento. A digressão feita até aqui teve dois objetivos: identificar na obra de Simonsen apontamentos para um projeto político pretensamente hegemônico; medir até que ponto o pensamento de Simonsen, que era identificado pari passu com o da direção do movimento de industriais, penetrou no pensamento da base da corrente industrialista em um locus particular.

Conclui-se que, apesar dos impasses e das dificuldades que o processo de elaboração político-intelectual apresentou, o I Congresso Brasileiro de 
Economia deve de fato ser considerado tanto um locus de consolidação ideológica do segmento industrial quanto de um projeto político hegemônico desse segmento. Apesar das dificuldades, foram claras as evidências da elaboração e homogeneização do pensamento industrialista.

Alguns pontos principais do projeto de recomendações ao governo, emergidas do Congresso:

- Organização corporativa da sociedade e do Estado.

- Difusão e prática do taylorismo nas empresas.

- Organização científica do trabalho no campo.

- Intervenção do Estado na economia sempre que (as entidades de classe julgassem) necessário.

- Criação de um Banco Central.

- Crescimento econômico planejado e acelerado.

A presença dos congressos industriais dos anos 1940 é evidente. Fica dos Congressos a própria hegemonia industrialista: nas décadas de 1950/60, a industrialização se tornou um valor, de modo que houve consenso ativo pelo crescimento acelerado e planejado. O corporativismo - herança do industrialismo, gênese do desenvolvimentismo no Brasil - preparou terreno para as alternativas autoritárias de desenvolvimento industrial e modernização "pelo alto".

\section{REFERÊNCIAS BIBLIOGRÁFICAS}

BIELSCHOWsKy, Ricardo Alberto. Pensamento econômico brasileiro - o ciclo ideológico do desenvolvimento. Rio de Janeiro: Contraponto, 2004 [1988].

Caetano, Coraly Gará. Desvendando mistérios: Roberto Simonsen e a luta de classes. 1994. 289 p. Tese (Doutorado em História) - Unicamp, Campinas, 1994.

CARone, Edgar. O pensamento industrial no Brasil (180o-1945). São Paulo: Difel, 1977. (Coleção Corpo e Alma do Brasil.) 
CEPÊDA, Vera A. Roberto Simonsen e a formação da ideologia industrialista no Brasil: limites e impasses. 2004. 346 f. Tese (Doutorado em Ciência Política) - Faculdade de Filosofia, Letras e Ciências Humanas, Universidade de São Paulo, São Paulo, 2004.

Congresso Brasileiro de Economia, 1. Anais... Tomo I, II, e III. Rio de Janeiro: Associação Comercial do Rio de Janeiro, 1943.

DraIBE, Sonia. Rumos e metamorfoses: Estado e industrialização no Brasil (1930/1960). Rio de Janeiro: Editora Paz e Terra, 1985.

Fanganiello, Helena. Roberto Simonsen e o desenvolvimento econômico. São Paulo: FEA/USP, 1970.

Gramsci, Antonio. Maquiavel, a política e o Estado Moderno. 3. ed. Rio de Janeiro: Civilização Brasileira, 1978.

KeYnes, John Maynard. Teoria geral do emprêgo, do juro e da moeda. Rio de Janeiro: Editora Fundo de Cultura, 1965.

List, Friedrich. Sistema Nacional de Economia Política. Tradução Luiz João Baraúna. São Paulo: Nova Cultural, 1989. (Coleção “Os Economistas”.)

Manollesco, M. O século do corporativismo - doutrina do corporativismo integral e puro. Tradução Azevedo Amaral. Rio de Janeiro: Livraria José Olimpio Editora, 1938.

MAZA, Fabio. O idealismo prático de Roberto Simonsen. São Paulo: FIESP, 2004.

Rompato, Maurílio. Roberto Simonsen e a evolução sem revolução. 2004. 384p. Tese (Doutorado em História) - Unesp, Assis, 2004.

Simonsen, Roberto. O trabalho moderno. São Paulo: seção de obras do "Estado", 1919.

Orientação industrial brasileira. São Paulo: Escolas Profissionais do Lyceu Coração de Jesus; CiEsP, 1928. As crises no Brasil. São Paulo: São Paulo Editora, 1931a. As finanças e a indústria. São Paulo: São Paulo Editora, 1931b. À margem da profissão - discursos, conferências e publicações. São Paulo: São Paulo Editora, 1932. 
Ordem econômica, padrão de vida e algumas realidades brasileiras.

São Paulo: São Paulo Editora, 1934.

Aspectos da política econômica nacional. São Paulo: Revista dos Tribunais, 1935.

História econômica do Brasil, 150o-1820. São Paulo: Companhia Editora

Nacional, 1937.

. A evolução industrial do Brasil. São Paulo: Revista dos Tribunais, 1939. Ensaios sociais, políticos e econômicos. São Paulo: FIESP, 1943.

O Plano Marshall e um novo critério nas relações internacionais. Rio de Janeiro: [s.n.], 1948.

VieIra, Rosa Maria. O pensamento industrialista de Roberto Simonsen: análise de ideologia. 1987. Dissertação (Mestrado em História Social) - FFLCH/USP, São Paulo, 1987.

\section{BIBLIOGRAFIA}

CARDoso, Fernando Henrique. Empresário industrial e desenvolvimento econômico do Brasil. São Paulo: Difusão Européia do Livro, 1964. (Coleção Corpo e Alma do Brasil.)

CARONE, Edgar. A Terceira República (1937-1945). 2. ed. São Paulo: Difel, 1982. (Coleção Corpo e Alma do Brasil.)

Corsi, Francisco. Estado Novo: política externa e projeto nacional.1. ed. São Paulo: Editora da UneSP, 2000.

Dean, W. A industrialização de São Paulo 1880-1945. São Paulo: Difel, 1976.

Furtado, Celso. A Pré-Revolução Brasileira. 2. ed. Rio de Janeiro: Fundo de Cultura, 1962.

Dialética Do Desenvolvimento. Rio De Janeiro: Fundo De Cultura, 1964. Desenvolvimento e subdesenvolvimento. 2. ed. Rio de Janeiro: Civilização Brasileira, 1968.

Formação econômica do Brasil. 27. ed. São Paulo: Companhia Editora

Nacional, 1998. 
GRAMSCI, Antonio. Os intelectuais e a organização da cultura. 4. ed. Rio de Janeiro: Civilização Brasileira, 1982.

Gudin, Eugênio. Para um mundo melhor: ensaios sobre o problema de após-guerra. Rio de Janeiro, Civilização Brasileira, 1943.

Rumos da política econômica - relatório apresentado à Comissão de Planejamento Econômico sobre Planificação da Economia Brasileira. Rio de Janeiro: Laemmert, 1945.

Hobsbawn, Eric. Era dos extremos: o breve século XX: 1914-1991. Tradução Marcos Santarrita. São Paulo: Companhia das Letras, 1995.

Luz, Nícia Vilela. A luta pela industrialização do Brasil. São Paulo: Alfa-Ômega, 1978. MarTins, José de Souza. A influência do café na industrialização e na formação da classe operária em São Paulo idem, O cativeiro da Terra. 7. ed. São Paulo: Editora Hucitec, 1998.

MARX, Karl H. A assim chamada acumulação primitiva. In: MARX, Karl H. O capital. v. II. São Paulo: Editora Nova Cultural, 1985.

A mercadoria. In: Marx, Karl H. O capital. v. II São Paulo: Editora Nova Cultural, 1985.

Miceli, Sérgio. Intelectuais e classe dirigente no Brasil. São Paulo; Rio de Janeiro: Difel, 1979.

MoOre JR., Barrington. As origens sociais da ditadura e da democracia: senhores e camponeses na construção do mundo moderno. Lisboa: Cosmos, 1975.

NuRske, Ragnar. Problemas de formação de capital em países subdesenvolvidos. Rio de Janeiro: Civilização Brasileira, 1957.

Simonsen, Roberto. A indústria em face da economia nacional. São Paulo: Revista dos Tribunais, 1937.

Os elos da indústria. São Paulo: FIESP, 1944.

Simonsen, Roberto C.; Gudin, Eugênio. A controvérsia do planejamento na economia brasileira; coletânea da polêmica Simonsen x Gudin, desencadeada com as primeiras propostas formais de planejamento da economia brasileira ao final do Estado Novo. Rio de Janeiro: IpEA/INPES, 1977. 